\title{
Density of Chikungunya Vectors and Platynectes beetles in the Rubber Plantations
}

\author{
Sheikh Afaq Gowhar* \\ ${ }^{1}$ College of public Health and Health Informatics, University of Ha'il, Ha'il Kingdom, Saudi Arabia
}

Received: December 18, 2017; Published: January 03, 2018

*Corresponding author: Sheikh Afaq Gowhar, College of public Health and Health Informatics, University of Ha'il, Ha'il Kingdom; Saudi Arabia; Email: mdxptu.sag@gmail.com

\section{Abstract}

Introduction: Chikungunya virus (CHIKV) is transmitted to humans through Stegomyia mosquitoes. Kerala was the worst affected State in India in 2007 with a total of 55.8\% of the reported Chikungunya fever cases in the country from the State (NVBDCP, India). Almost all the districts of Kerala were affected with the infection during 2006-2007.

Methodology: Population density of beetles in the latex collection containers was evaluated once in fortnightly in all the three study areas, Aimcompu, Chethackal and Pampady. Fixed latex collection containers and discarded latex collection containers in rubber plantations were surveyed to find out the beetle density.

Results: The seasonal density of Platynectes beetles in the rubber plantations was studied in all the three areas. Platynectes beetles were found in the latex collection containers in the rubber plantations and the population density of the beetles per latex collection container was found to be maximum during the south-west monsoon season which contributes $50 \%$ rainfall annually rubber plantations of Kerala.

Conclusion: Temperature increased, the occurrence of Platynectes beetle reduced in the LCC which increased the density of juveniles of St. Albopicta in latex collection containers results the improved adult density of St. albopicta in the rubber plantation sectors of Kerala. The minimum temperature and maximum rain recorded in the study areas during southwest monsoon, which contributes almost $50 \%$ rainfall yearly.

Keywords: Chikungunya virus; Kerala; Infection; Climate; Rubber plantation; Beetles

\section{Introduction}

Fifteen States and Union Territories in India witnessed major outbreaks of Chikungunya virus (CHIKV) infection since 2005. During 2007, 3.6 million fever cases were recorded compared with about 1.38 million in 2006 and 1.2 million in 2005, most estimates drawn from, epidemiological, geographical and demographic data [1]. Chikungunya virus (CHIKV) is transmitted to humans through Stegomyia mosquitoes. Kerala was the worst affected State in India in 2007 with a total of $55.8 \%$ of the reported Chikungunya fever cases in the country from the State (NVBDCP, India). Almost all the districts of Kerala were affected with the infection during 2006-2007. The factors attributed to this outbreak were the crucial mutation "A226" acquired by the virus in 2007 and the abundance of the vector species Stegomyia albopicta in the region [2]. St. aegypti and St. albopicta, the vectors for CHIKV were widely distributed and abundant during the pre and post monsoon season. The prevailing climate, terrain and agricultural practices in these districts were conducive for the breeding of St. albopicta /St. aegypti, the vector of Chikungunya and Dengue in Kerala.
The worst affected region was the mid-highland regions which harbour the vast rubber plantation sectors in the State. The hilly and semi-forested districts of Kottayam and Pathanamthitta were the most affected districts during 2007 epidemic, which constitutes the major portion in the rubber plantation sectors of Kerala. About $63.0 \%$ of people living in the rubber plantation areas (Kerala contributes $80.0 \%$ of the rubber production in India), was afflicted with this disease [3], St. albopicta acted as main vector species [2]. Incidence of Dengue fever, another mosquito borne arbo-viral disease is also on an increasing trend in Kerala [4]. St. albopicta (Skuse) 1894 (Dipteral: Culicid), the predominant Stegomyia species prevalent in Kerala was recorded as the vector species of both these arbo-viral diseases [5]. Innumerable Discarded Latex Collection containers (DLCCs), unused Fixed Latex Collection Containers (FLCCs), and tree holes, leaf axils of pine-apple plants and fallen leaves of areca-nut tree etc.

Were recorded the key breeding habitats of this species in rubber plantation sectors in Kerala [3,6]. Dengue a vector - borne 
and emerging infectious disease is estimated to affect 50-100 million individuals each year in tropical and subtropical areas $[7,8]$. Demographic and societal changes, such as population growth, unplanned urbanization, microevolution of the virus, climatic change and modern transportation, have greatly contributed to the increased incidence and geographical spread of Dengue virus infection in recent decades and distributed among about 120 countries globally. Dengue was first recognized in the 1950s during its epidemic in the Philippines and Thailand [9]. Dengue is caused by four serologically distinct types of Dengue virus. DENV-1, DENV-2, DENV-3 and DENV-4, belonging to the family Flaviviridae, genus Flavivirus. The viruses are transmitted to human beings through the bite of Stegomyia mosquitoes such as St. aegypti and St. albopicta which are considered as primary and secondary vectors of Dengue respectively [9]. The incidence of Dengue fever has increased significantly around the world in recent decades. About half of the global population lives under the risk of infection of this arbo-viral disease [10]. St. albopictais becoming an increasingly important vector of Dengue because of its rapidly changing global distribution [11] and it is generally believed to be a less efficient vector of arboviruses than St. aegypti. St. albopictais highly adaptive and therefore can survive even in cooler temperate regions. Its spread to new areas is due to its tolerance to temperatures below freezing, hibernation and ability to shelter in microhabitats [9]. St. albopictais an aggressive day-biting species known in different parts of the world including South East Asia [12], and Southern China [13]. Worldwide trade in second hand tires transported to various places, which often contain water could be an ideal place for eggs and larvae of these mosquitoes, has been a key factor in the large-scale conquest of St. albopicta in new areas which easily adapts to new environments, even in a temperate climate. This expansion is creating new opportunities for viruses to circulate in new areas, becoming a common cause of epidemics in St. aegyptifree countries from Hawaii to Mauritius. However St. albopicta is considered as an inefficient vector of Dengue because not well adapted to urban domestic environments and is less anthropophilic than St. aegypti. The Asian tiger mosquito (St. Albopicta) belongs to the East and Southeast Asia, where it originally lived at the edges of forests, breeding in tree hole, containers and other natural reservoir [11].

The entire population of India is under the risk of Dengue. In India the first case of Dengue has been reported from Kolkata (previously Calcutta) during 1963. The number of Dengue cases had been an increasing trend since 2001 and the maximum number of suspected cases (28055) has been recorded during 2010.In Kerala Dengue fever was first recorded in Kottayam District in 1997 [14]. This district continues to contribute the maximum number of cases of Dengue fever in the State, next to Trivandrum District in the south Kerala every year. Topographically, Kottayam District is semi-forested region with hills and hillocks located at the foothills of the Western Ghats. This district is the abode of rubber plantations in the country and grows rubber in about $60 \%$ of its net sown area under agriculture. St. Albopictathe vector of Dengue fever is abundant throughout the plantation belt of Kerala, including Kottayam District [3]. All the four Dengue serotype are prevalent in the State, however, Dengue 2 and 3 are the major serotypes prevalent in Kerala State [4].In India the first outbreak of Chikungunya Virus occurred at Kolkata in 1963 and was followed by Chennai, Puducherry (previously Pondicherry), Vellore and Maharashtra in 1964, another outbreak was reported from Nagpur and Barsi of Maharashtra in 1973. The virus again re-emerged in 2006 after a gap of 32 years and caused an explosive outbreak affecting several States (Directorate of National Vector borne disease control programme, 2007), and the attack rate was more than $60 \%$ of the population. The virus is a single strand RNA virus belongs to family Togoviridae, genus Alpha virus.

The first outbreak of Chikungunya has been reported from African continent Tanzania in 1953. In Indian Ocean Island's the outbreak of Chikungunya occurred in early 2005 [15], after that it spread to adjoining areas and emerged in peninsular India in late 2005 [16]. In India worst affected States were Andhra Pradesh, Karnataka, Maharashtra, Madhya Pradesh, Tamil Nadu, Gujarat and Kerala. In Kerala the first epidemic was reported in 2006 affecting more than 70, 000 people (Directorate of National Vector Borne Disease Control Programme, 2006), followed by another in 2007 of all the 14 districts in which Pathanamthitta, Idukki and Kottayam districts were worsted affected where rubber plantations, acts the key breeding source of St. albopicta, which would have supported the recent widespread outbreak of Chikungunya fever in the State [3].The virus isolated from these areas belonged to the African genotype different from the viruses circulating in 1963-1973, which belonged to the Asian genotype $[17,18]$. St. aegypti and St. albopicta are the vectors of Chikungunya, however St. albopictais considered the main vector in Reunion and other islands in the Indian Ocean. St. Aegypi was considered as the principal vector of Chikungunya in Asia including India [1] (Figures 1-4).

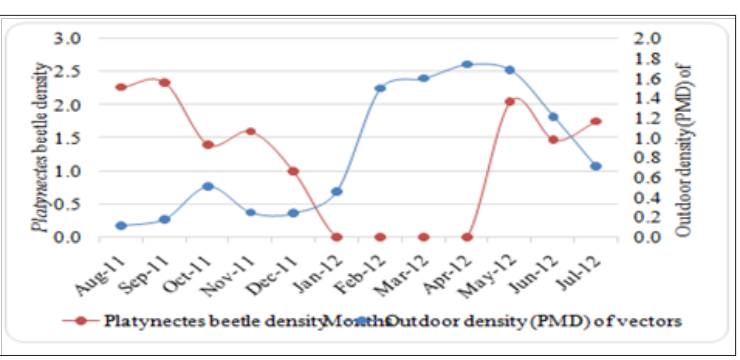

Figure 1: Vector density (PMD) and Platynectes beetles density (per positive LCC) in the rubber plantations.

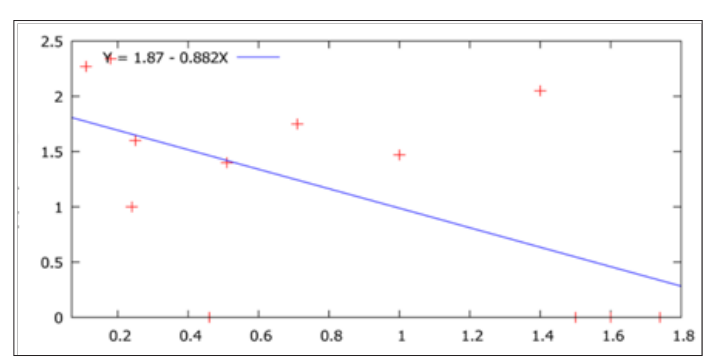

Figure 2: Negative correlation between vector density (PMD) and Platynectes beetle density (per positive LCC)) in the rubber plantations. 


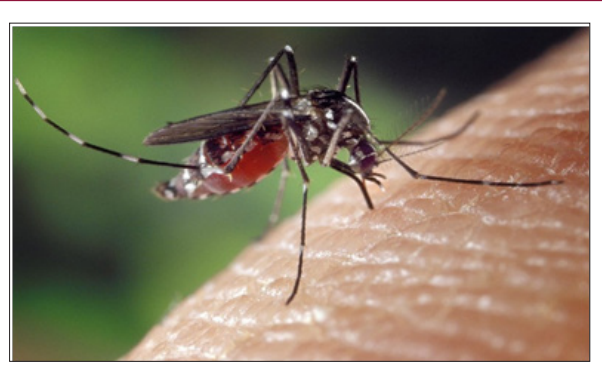

Figure 3: Stegomyia albopicta (Adult).

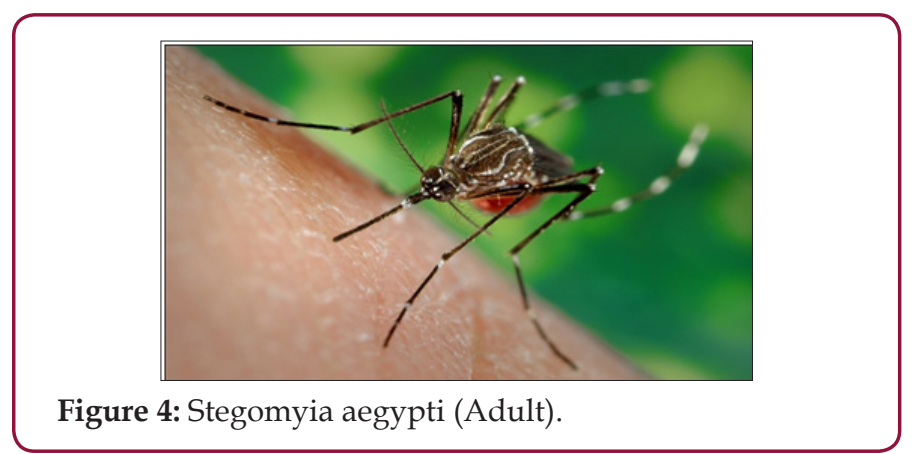

Breeding of both St. albopicta and aegypti species occur in variety of domestic and peri-domestic habitats. The breeding habitats of St. albopictahave been also recorded in natural habitats such as tree holes and bamboo stumps. In South-East Asian countries, this species is also known to be well established in artificial containers such as jars, tin cans, bottles and also around human dwellings [19]. The breeding habitats of St. mosquitoes were found
a) Natural
b) Domestic
c) Rubber tires
d) Water and sewage-disposal installations
e) Building equipment and parts of machinery and boats.

The domestic containers were those directly associated with the household and were used for such purposes as water storage, ornamentation containers, flower vases and flower pots [19]. The natural breeding habitats of these species have also been found in bamboo bushes and rock pits [20]. The rubber plantations of Kerala located at the foothills of Western Ghats on the western coast of India, is the second largest mountainous region of India (after the Himalayas, Anaimudi - 2694 m), on the western side of the Deccan Plateau. Evergreen rainforests constitute $40.0 \%$ of the Western Ghats with a mean altitude of more than $900 \mathrm{~m}$ MSL. The rest of the area is under cultivation with cash crops such as rubber, are canut, cardamom, pineapple, nutmeg, pepper etc.

United Nations Educational Scientific and Cultural Organization (UNESCO) inscribed Western Ghats as one of the World's Natural Heritage, in India, and it is one of the eight hotspots of biodiversity globally and has over 5000 species of flowering plants, 139 mammal species, 508 bird species, 179 amphibian species, it is likely many undiscovered species in this range, 325 globally threatened species. The range runs north to south, on the western edge of Deccan plateau of India. We recorded the occurrence of a beetle species (Coleopteran: Dytiscidae), natural predator to the immature of St. albopicta, in Fixed Latex Collection Containers (FLCCs) and Discarded Latex Collection Containers (DLCCs), the key breeding habitats of this major vector species in Aimcompu, Kottayam District $\left(09^{0} 464.77^{\prime}\right.$ N; $76041.113^{\prime}$ E) during 2009. This Coleopterabeetle was taxonomically identified by Natural Museum History, London (NHM), as belonging to a new species of the genus Platynectes (Family: Dytiscidae) Subfamily: Colymbetinae, Tribe: Agabini. Field investigations in Pampady 090 32. 457' N; 760 $38.952^{\prime}$ E, of Kottayam District) and Chethackal (090 26.241' N $76048.440^{\prime}$ E) of Pathanamthitta District) also revealed natural occurrence of this beetle species in rubber plantation areas. In both the areas the beetle was also found predatory to St. albopicta immature. Hence, we undertook a systematic and scientific study to understand some ecological aspects of this predatory beetle. The natural habitat of the beetle was found to be the water bodies such as fresh water ground pools and pits in the rubber plantations. They invade the rubber latex collection containers, fixed at 3.5 to 5 $\mathrm{m}$ above from the ground level, which support abundant breeding of St. albopicta.

\section{Study Areas}

The hilly and forested districts of Kottayam and Pathanamthitta located in the mid-high lands region of Kerala were the worst affected by CHIKV, contributing to $44.33 \%$ and $14.37 \%$ of the total cases, respectively [2].These districts have abundant rubber plantations [109, 582 ha in Kottayam (the largest area in the State) and 61,016 ha in Pathanamthitta], which supported prolific breeding of St. albopicta, the main vector of Chikungunya infection [2]. They breed in the rainwater that accumulates in the hemispherical containers, fitted to the trunks of rubber trees for latex collection in the region [2]. The population of districts, Pathanamthitta, Idukki and Kottayam [21] is 1,234,016, 1,129,221 and 1,953,646, respectively. The CHIKV suspected fever cases reported from Kerala health records from these districts during 2007 (cases were recorded during May-October) were only 3,456 (0.28\%), 538 (0.05\%) and $10,662(0.55 \%)$ respectively. The percentage of persons infected with CHIKV IgG to be70.9\%, 74\% and 59.7\%, respectively, in these areas. Prevalence of CHIKV fever (from history) in Chethackal, and Aimcompu areas was $80.6 \%$, and $74.2 \%$, respectively [3]

The study areas via, Aimcompu, Chethackal and Pampady are located in the central region of Kerala State which were worst affected; during 2007 Chikungunya virus outbreaks were selected for this study. These areas were located in the geographical zones of mid-highland semi forests area of Kerala State. India is the third largest producer, fourth largest consumer of natural rubber in the world. The total area under forests is $28 \%$ more than the countries average forest area which also constitutes the Western Ghats of Kerala. Also the Western Ghats has unique property as hot spot of biodiversity among the world's eight hotspots of biodiversity and these rubber plantations are located at the foothills of the Western 
Ghats of Kerala. Physical map of the study areas in the rubber plantations of Kerala is shown in Figures 5 \& 6 .

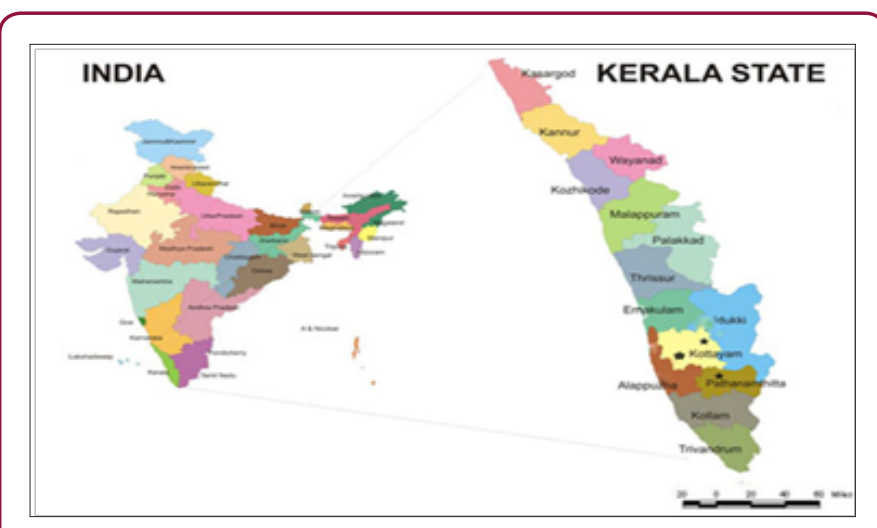

Figure 5: Physical map of the study areas in the rubber plantations located at the foot hills of Western Ghats of Kerala.

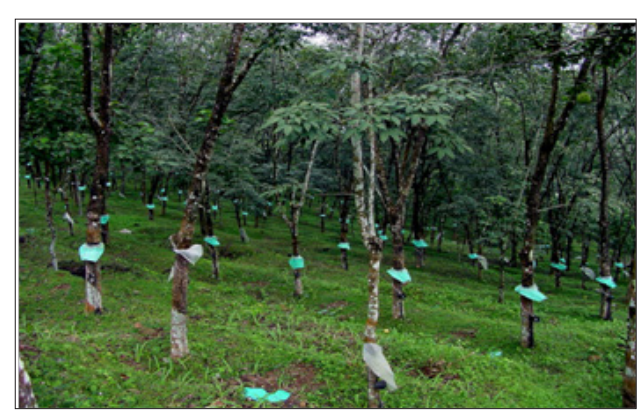

Figure 6: Rubber Plantations of Kerala.

The most predominant mosquito species in the rubber plantations of Kerala have been recorded St. albopicta which constitutes $62 \%$ of total species. The average resting density of the species per month was 0.05 as compared to outdoor resting density 1.57 shows an exophilic species [22]. The species was prevalent throughout all seasons of the year with peak abundance during the pre-monsoon months March - May, during this period there was an intermediate showers of rain (18.96\% of total annual rainfall), with the rainy days ranging from 8-17 per month and minor peak during Nov-Dec. Fixed latex collection containers (FLCCs) and discarded latex collection containers (DLCCs) constitutes $63.89 \%$ of breeding habitats of the species in the rubber plantations [22].

\section{Aimcompu}

Aimcompu village ( $09^{0} 464.77^{\prime} \mathrm{N}$; 760 41.113' E), in Kottayam district, supports the rubber plantations, where 66105.7 hectares under private sector. The area is located in Kadanadu Panchayat, Meenachil Taluk, Kottayam district. Meenachil taluk contributes $44.7 \%$ of rubber plantation area in Kottayam district. The rubber plantation area of this study area is approximately 280 hectares. This area was severely affected by the outbreak of Chikungunya in Kottayam during 2007. Rubber is the major cash crop cultivated in this area covering 101.73 hectares of land. Other agricultural products in the study area are pineapple, coconut, areca nut, coconut and paddy cultivation.

\section{Chethackal}

Chethackal (090 26.241' N 760 48.440' E) in Pathanamthitta District, which supports 220 hectares of rubber plantations, out of total area 254 under Rubber Research Institute of India (RRII)]. The area of Chethackal is located in the district Pathanamthitta, Tehsil Ranni which supports the rubber plantation of 220 hectares out of total area 254.6 hectares in the area and $60 \mathrm{kms}$ away from district Kottayam. The rubber plantation is under the Rubber Research Institute of India (RRII) Govt. of India Ministry of Commerce. The plantation is divided into two parts division A and division $\mathrm{B}$. The population in these divisions was affected by Chikungunya more than $70 \%$ [17].

\section{Pampady}

Pampady (090 32. 457' N; 760 38.952' E) in Kottayam District, which supports the small scale rubber plantations under private public sector only. Pampady is located outskirts of Kottayam district $20 \mathrm{kms}$ away from Kottayam town, semi- urban area of Kerala supports small scale rubber plantation of Kerala. The seroprevalence of Chikungunya infection recorded in these areas much higher $(68 \%)$ compared to the similar CHIK outbreaks in many other parts of the world [17].

\section{Materials and Methods}

As the beetles invade in latex collection containers ( LCCs), both fixed latex collection containers (FLCCs) and discarded latex collection containers (DLCCs), which are 3-5 meters above the ground level, containing various stages (first to fourth instars) of the mosquito larvae, acts as key breeding habitats of St. albopicta in the rubber plantations. Surveys were carried out in the 3 study areas in Kerala State, for a period of one year (2011-2012) to understand its population parameters. Population density of beetles in the latex collection containers was evaluated once in fortnightly in all the three study areas, Aimcompu, Chethackaland Pampady. Fixed latex collection containers and discarded latex collection containers in rubber plantations were surveyed to find out the beetle density. The number of wet containers which are positive for beetles in the study areas were observed. The whole content of water from positive FLCCs and DLCCs were transferred to the enamel trays for observing the density of the beetles in each container [23]. Enamel trays and pipettes were used for the study of population density of the beetles in the rubber plantations. The study was continued for a year, sampling 200 trees in each village, once in fortnight. These were selected in 4 radials from a fixed point, covering about 50 trees in a radius [24]. After completing the first row up to 50 trees (latex collection containers), second row of trees was surveyed in the opposite direction of the first row. The distance in all the four directions was same, as each rubber tree is fixed at same distance from each other. The trees were marked during the observation every fortnightly. Next fortnight survey, the densities of the Platynectes sp. were observed in the next field area which was not surveyed in the previous survey. The total area covered using this sampling procedure was about 20 ha of rubber plantations in each village. These three villages were selected as 
these were worst affected by Chikungunya outbreak during 2007 and they represented both large and small scale rubber plantations.

\section{Vector Density (st. albopicta) and Platynectes beetle Density in the Rubber Plantations}

Surveys were also carried out to analyse the vector population density and the Platynectes beetle population density in Aimcompu and Chethackal for the period of one year. To calculate outdoor per man hour density of vectors (St. albopicta), the sweep nets and drop nets were used to collect St. albopicta from the rubber plantations [23]. Outdoor resting collections (ODRC) (both sweep net and drop net) were carried out in an area of $0.5 \mathrm{Sq} \mathrm{Km}$, which corresponded with the study area selected for the population estimates of beetles. Both beetle and St. Albopicta surveys were carried out in the same areas to study the density of both in the rubber plantation sectors. The drop net gives an estimate of the absolute outdoor population resting species of mosquitoes [23]. Sweep nets collections were carried out in area where drop net not possible.

\section{Results and Discussions}

\section{Density of Platynectes sp. nov. in the rubber plantations}

\section{Seasonal distribution}

The seasonal density of Platynectes beetles in the rubber plantations was studied in all the three areas. Platynectes beetles were found in the latex collection containers in the rubber plantations and the population density of the beetles per latex collection container was found to be maximum during the southwest monsoon season which contributes 50\% rainfall annually rubber plantations of Kerala. It was found that the maximum density of the beetles per latex collection container vary in different months, ranging from 1.0-3.8 per latex collection container in all the study areas. Maximum density was recorded at Aimcompu (3.8) during the month of September. The average density of Platynectes beetles per LCC was found (2.34) from all study areas, during the monsoon season. Beetles were not found in LCCs from January to April which contributes only $272 \mathrm{~mm}$ of rainfall (annual rainfall $2991 \mathrm{~mm}$ ). The minimum density of beetles per latex collection container was recorded in the study areas, Aimcompu and Chethackal from months of November and October respectively (northeast monsoon which contributes $20 \%$ of rainfall).However minimum density of beetles per LCC in study area Pampady was recorded from months of June, October and December (during these months 1 beetle per LCC). During pre-monsoon month of May and post monsoon month of December, density of Platynectes beetles was recorded from Pampady and Aimcompu area. The beetles were found predatory on St. albopictalarvae abundant in the rubber plantations.

\section{Temporal Distribution}

The density of Platynectes beetles per latex collection container increases with the increase of rainfall in the monsoon seasons, starts from pre monsoon and reaches to maximum during southwest monsoon and again declines to minimum during northeast monsoon. The highest density of the beetles recorded in the all three study areas in the rubber plantation sectors of Kerala during June to September (southwest monsoon with an average rainfall
$1434.5 \mathrm{~mm}$ (annual rainfall $2911 \mathrm{~mm}$ ). The density of beetles in the LCCs was found during the months of May to November, June to October and June to December in Aimcompu, Chethackal and Pampady respectively.

\section{Vector Density (st. Albopicta) and Platynectes Beetle Density in the Rubber Plantations}

The study clearly found that when beetle density was high, the vector population density was comparatively low. With the increase of density of Platynectes sp. in the key breeding habitats (LCCs) of St. albopicta, the density of the mosquitoes fper man hour density (PMD)\} decreased in the rubber plantation sectors and vice versa (Table 1). The peak density of the St.albopicta was recorded in the month of April, when Platynectes beetles were not recorded in the LCCs. Also Platynectes sp. nov. Was not recorded from the month of January to April in the LCCs when the density of the mosquitoes (PMD) was found maximum. The observations indicate that the density of Platynectes sp. Nov. check (biologically) the population density of St. albopicta in the rubber plantation sectors of Kerala. The density of the beetles in the key breeding habitats of St. albopicta per month and St. albopictadensity (per hour man density) recorded throughout the year in the study areas is shown in Figure. 1. However there was an overall negative linear correlation( $r=-0.589, p=0.048$ ), for the temporal population densities of Platynectes beetles with St. Albopictain the rubber plantation sectors of Kerala India [24-33].

Table 1: Vector density (St. albopicta) and Platynectes beetle density in the rubber plantations

\begin{tabular}{|c|c|c|}
\hline Months & $\begin{array}{c}\text { Outdoor density (PMD) } \\
\text { of vectors }\end{array}$ & Platynectes beetle density \\
\hline Aug-11 & 0.11 & 2.27 \\
\hline Sep-11 & 0.18 & 2.34 \\
\hline Oct-11 & 0.51 & 1.4 \\
\hline Nov-11 & 0.25 & 1.6 \\
\hline Dec-11 & 0.24 & 1 \\
\hline Jan-12 & 0.46 & 0 \\
\hline Feb-12 & 1.50 & 0 \\
\hline Mar-12 & 1.60 & 0 \\
\hline Apr-12 & 1.74 & 0 \\
\hline May-12 & 1.68 & 2.05 \\
\hline Jun-12 & 1.21 & 1.47 \\
\hline Jul-12 & 0.71 & 1.75 \\
\hline
\end{tabular}

Temperature increased, the occurrence of Platynectes beetle reduced in the LCC which increased the density of juveniles of St. Albopicta in latex collection containers results the improved adult density of St. Albopicta in the rubber plantation sectors of Kerala. The minimum temperature and maximum rain recorded in the study areas during southwest monsoon, which contributes almost $50 \%$ rainfall yearly. During this time period, the dominance and density of Platynectes beetle recorded maximum in the LCCs in all the study areas in the rubber plantation areas of Kerala. The maximum temperature and minimum rainfall has recorded from 
January to April, when the beetles were not predominant in the LCCs in the study areas. Statistically it has shown the shower and temperature are favorable for the occurrence and density (per positive LCC)) of Platynectes beetles in the main breeding habitats of St. albopicta in the rubber plantations during pre-monsoon, The rainfall is the naturally favorable factor for the breeding of the St. albopicta. When ra-in water is stored in the LCCs, increases the chances of St. albopicta breeding in these territories. Plenty of rainy water pools (LCCs) is suitable for St. Albopicta breeding. However in the rubber plantation subdivisions of Kerala, monsoon seasons are active mainly southwest monsoon which contributes the closely $50 \%$ rainfall yearly and provides maximum number of rainfall days repeatedly during these periods. The same interval of time is the promising season for St. Albopicta breeding in the rubber plantations. Summer season which is not providing the continuous rainy days for breeding of these species and contributes only $22 \%$ rainfall yearly? The St. albopicta breeds only in tree holes, forest edges containers and natural reservoirs, Temperature is additional biologically favorable feature for the breeding of St. albopicta and normal temperature is suitable for the breeding of St. albopicta. The lowest temperature (24.06 0C) was documented during the monsoon periods in the rubber plantations as associated to summer season. When the temperature rises above normal the breeding chances for St. Albopicta convert less.

Number of rainfall days per month maintains continuous water in the breeding habitats and delivers suitable atmosphere for breeding of St. Albopicta in the LCCs in the rubber plantations of Kerala. Temperature also offers the appropriate situation for the breeding of St. Albopicta. Both these reasons are promising for the breeding of St. Albopicta concurrently during the monsoon seasons. Our studies indicated that vector density is low during this monsoon Seasons as related to the summer season in the rubber plantations. This is due to the prevalence of Platynectes beetles in the main breeding habitats of St. Albopicta. Henceforth the density of St. Albopicta is plaid by Platynectes beetles in this province during the rainy seasons. Climatic factors like number of rainy days and temperature impacts the ecology of the beetles which are destructive to the Dengue and Chikungunya vectors in the rubber plantations of Kerala. The climatic issues play a dynamic role of the communication of Platynectes beetles and immature of St. Albopicta in the significant breeding habitats, LCCs in the plantation areas of Kerala. These climatic factors viz. rainwater showed optimistic linear correlation and temperature indicated negative linear correlation with the density and dominance of beetles in the key breeding Environments. The rainy days diverse 23 to 6 from August to December in the all the three study zones, during this time the density of the Platynectes beetles diverse from 3 to 1.5 per LCC in Aimcompu, from 1.94 to 0 per LCC in Chethackal and from 1.7 to 1 per LCC in the Pampady. From January to March the number of rainy days varied from 6 to 9 (minimum no. of rainfall days annually), during the same time density ruins zero in all the study areas. However when the number of rainy days upsurges from 10 to 22 during May to July, the density of Platynectes beetles diverse from 2.04 to 1.53 .

\section{Acknowledgement}

The Author is highly thankful to the Dean of the College Dr Abdullaha Hamyainie and Head of the Department Dr Hamid Er Nourina for their support and suggestion to finalize the work in the current shape

\section{References}

1. Kalantri SP, Joshi R, Riley LW (2006) Chikungunya epidemics: An Indian perspective. The National medical journal of India 19(6): 315-332.

2. Kumar NP, Joseph R, Kamaraj T, Jambulingam P (2008) A226V mutation in virus during the 2007 chikungunya outbreak in Kerala India. Journal of General Virology 89: 1945-1948.

3. Kumar NP, Suresh A, Vanamail P, Sabesan S, Krishnamoorthy K, et al. (2011) Chikungunya virus outbreak in Kerala, India, 2007. A seroprevalence study. Memórias do Instituto Oswaldo Cruz 106(8): 912-916.

4. Kumar NP, Jayakumar RP, George K, Kamaraj T, Krishnamoorthy K, et al (2013) Genetic characterization of dengue viruses prevalent in Kerala State. Journal of Medical Microbiology 62: 545-552.

5. Thenmozhi V, Hiriyan JG, Tewari SC (2007) Natural vertical transmission of dengue virus in Aedes albopictus (Diptera: Culicidae) in Kerala, a southern Indian state. Japanese Journal of Infectious Diseases 60(5): 245-249.

6. Sumodan PK (2003) Potential of rubber plantations as a breeding source for Aedes albopictus in Kerala India. Dengue Bulletin 27: 197-198.

7. Gubler DJ (2006) Dengue/dengue haemorrhagic fever: history and current status. In New Treatment Strategies for Dengue and Other Flaviviral Diseases, Novartis Foundation Symposium 277: 3-16.

8. Halstead SB (2007) Dengue. The Lancet 370(9599): 1644-1652.

9. WHO (2015) Dengue and sever dengue. Fact sheet N0 117.

10. WHO (2009) Dengue: Guidelines for Diagnosis, Treatment, Prevention and Control. Geneva: World Health Organization 1-17.

11. Rezza G (2012) Aedes albopictus and the re-emergence of Dengue. BMC Public Health 12:72.

12. Russell PK, Gould DJ, Yuill TM, Nisalak A, Winter, et al. (1969) Recovery of dengue-4 viruses from mosquito vectors and patients during an epidemic of dengue haemorrhagic fever. The American Journal of Tropical Medicine and Hygiene 18(4): 580-583.

13. Qui F, Zhang H, Shao L, Li X, Luo H, et al. (1981) Studies on the rapid detection of dengue virus antigen by immunofluorescence and radioimmunoassay. Chinese Medical Journal 94(10): 653-658.

14. Kalra NL and Prasittisuk C (2004) Sporadic prevalence of DF/DHF in the Nilgiri and Cardamom hills of Western Ghats in South India: is it a seeding from sylvatic dengue cycle - a hypothesis. Dengue Bulletin 28: $44-50$.

15. Schuffenecker I, Iteman I, Michault A, Murri S, Frangeul L, et al. (2006) Genome Microevolution of Chikungunya Viruses Causing the Indian Ocean Outbreak. PLos Medicine 3(7): 1058-1070.

16. Lahariya C, Pradhan SK (2006) Emergence of chikungunya virus in Indian subcontinent after 32 years: a review. Journal of Vector Born Disease 43: 151-160.

17. Kumar NP, Madhu Mitha M, Krishnamoorthy N, Kamaraj T, Joseph R, et al. (2007) Genotyping of virus involved in the 2006 Chikungunya outbreak in South India (Kerala and Puducherry). Current Science 93(10): 14121416.

18. Yergolkar PN, Tandale BV, Arankalle VA, Sathe PS, Sudeep AB et al. (2006) Chikungunya outbreaks caused by African genotype, India. Emerging Infectious. Disease 12(10):1580-1583. 
19. Chan YC, HO BC, Chan KL (1971) Aedes aegypti (L.) and Aedes albopictus (Skuse) in Singapore City. Bulletin of the World Health Organization 44(5): 629-633.

20. Kumari R, Kumar K, Chauhan LS (2011) First dengue virus detection in Aedes albopictus from Delhi, India: its breeding ecology and role in dengue transmission. Tropical Medicine and International Health 16(8): 949-954.

21. Census of India (2001).

22. (2010) Vector control Research Centre, Annual report 27.

23. Service MW (1976) Mosquito ecology-field sampling methods. Elsevier Applied Science Publishers Ltd., London 43-62.

24. Southwood TRE (1978) Ecological methods with particular reference to the study of insect population, second edition, University Printing House Cambridge 1-218.

25. Census of India 2011. Provisional population totals.
26. Kumar NP, Bashir A, Abidha S, Sabesan S, Jambulingam P (2014) Predatory potential of Platynectes sp. (Coleoptera: Dytiscidae) on Aedes albopictus, the vector of dengue/ chikungunya in Kerala, India. Journal of Tropical Biomedicine 31(4): 736-741.

27. Lewis C 2012 " 39 sites in Western Ghats get world heritage status" TNN Jul 3, 2012, 04.02AM IST (2012-07-03). The Times of India. Retrieved 2013-0221.

28. Myers N, Mittermeier RA, Mittermeier CG, Fonseca Da Ga, et al. (2000). Biodiversity Hotspots for conservation priorities. Nature 403(6772): 853-858.

29. (2006)National Vector Borne Diseases Control Programme, Chikungunya fever situation in the country during.

30. (2007) National Vector Borne Disease Control Programme (NVBDCP), Govt. of India, New Delhi.

31. WHO (2004) Global strategic framework for integrated vector management. Geneva, World Health Organization 1-12.

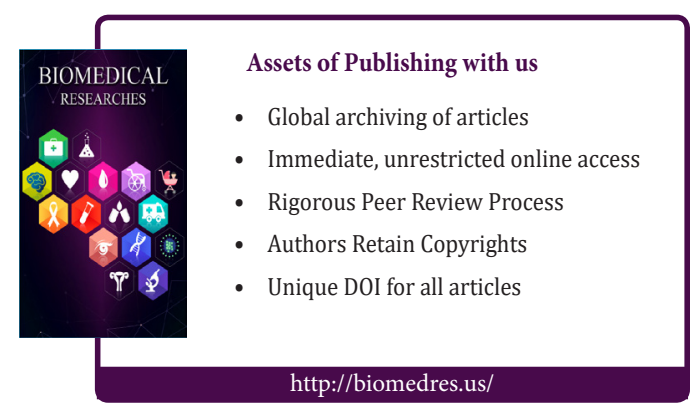

